\title{
The Future of Green Cities in 2040: A Case Study on the Capital City of Qatar, Doha
}

\author{
Ali Abdallah \\ Tourism Management Department, Stenden University of Applied Sciences, Doha, Qatar \\ Email address: \\ aabdallah@stenden.edu.qa

\section{To cite this article:} \\ Ali Abdallah. The Future of Green Cities in 2040: A Case Study on the Capital City of Qatar, Doha. Humanities and Social Sciences. \\ Vol. 8, No. 6, 2020, pp. 170-176. doi: 10.11648/j.hss.20200806.11
}

Received: October 11, 2020; Accepted: October 22, 2020; Published: October 30, 2020

\begin{abstract}
As part of Qatar's national vision for 2030, environmental sustainability has been put forward as an important aspect to develop for the future of the country [13]. Youssef [25] states that while the urban growth of Qatar is a somewhat recent phenomena, $99 \%$ of the country's population reside in cities. This has led to several challenges, such as an increase in water, and electricity consumption, increase in waste, and polluted air quality. Thus, in order to manage these long term sustainable urban development challenges, Qatar has emphasized the importance of sustainable and green cities, such as Msheireb Downtown Doha. The aim of this research is to create scenarios about sustainable living in Qatar. The research begins with a PESTLE analysis of the country, from which the most important driving forces are derived. The extremes of the drivers are then elaborated upon, from which four scenarios are created and described in detail. Consequently, future strategic options are derived out of the scenarios, and the most feasible, and realistic options are chosen for each scenario in this research. Lastly, the options are reflected upon, and the research is completed with a conclusion at the end.
\end{abstract}

Keywords: Green Cities, Qatar Tourism, Tourism Development, Tourism Planning

\section{Introduction}

As Artmann et al. [1] observe, by the end of the $21 \mathrm{st}$ century, $90 \%$ of the world's population will be located in urban areas. Therefore, it is important to understand the notions of developing urban infrastructure that are sustainable for future generations. Green cities are an important component of the urban sustainable development, and of smart economies of the future.

Zaina, Zaina \& Furlan [26] state that the city of Msheireb Downtown Doha aims to conserve the historic city of Doha by creating a sustainable lifestyle through the combination of modern architecture and traditional community living. As sustainable developments are based on planned economic strategies, and community lifestyle changes, the focus has shift from building infrastructure around roads, to accommodations around metro stops of the rail system.

Moreover, Qatar is also a transit hub, owing to its geographical location that allows routes connected to Africa, and Europe. Additionally, as Qatar aims to transform itself into a tourist attraction, it also has the focus on its cultural development as a form of tourism for visitors.

Qatar has also emphasized on the increase in education for its local community, making it another source of sustainable growth for the country. Lastly, it has become a destination for business tourism, and regional political debates occurring in Qatar.

For Wiedmann, Salama \& Mirincheva [23], the investment hub is the most important aspect to focus on for sustainable development of the country. Furthermore, transit, tourism, and knowledge hub are the important fields to focus on for developmental strategies for the country's growth in the next 10-20 years.

The vision of the country's future also includes the compatibility between the economic growth, social growth, and the conservation of its natural habitat. Moreover, Rizzo [16] observes that Qatar has focused on sustainable aspects in its urbanization on a smaller scale than other cities in the Gulf, while it is an ambitious goal at the same time since it aligns with delivering the eco-friendly FIFA World Cup 2022.

According to Klooster \& Asselt [9], studying the future has several challenges. The main evident challenge is the unknowability of the future, and often the reason is the lack of resources needed to obtain, combine, and measure data about the past and the present environment of a scenario. The aim of this research is to create clear and relevant scenarios for sustainable living in Qatar. The research analyses Qatar and its capital city Doha, then creates relevant scenarios for sustainable living. 
Two driving forces are chosen and are seen as the structure of constructing scenarios that help predict the environment of the future, and how the drivers would be in the terms of uncertainty, and impact [24].

\section{Future Scenarios}

\subsection{Approaching the Topic and Time Horizon}

\subsubsection{Political Factors}

While the state of Qatar is a monarchy, it holds elections on a municipal level. Municipal leaders then have the opportunity to share the grievances of their municipals to the government. The government also manages the overall country, and the infrastructure of its various cities. Additionally, despite have regional tensions in the Gulf, Qatar has extremely low rates of crime, and is considered a safe destination, and a secure investment option [6].

\subsubsection{Economic Factors}

According to Reuters [15], despite the regional blockade places on the country, the economic environment is relatively stable, with the economy of Qatar being supported by the oil and gas exports, and other diversified sources such as growing tourism, and sustainable development in the country [12].

\subsubsection{Social Factors}

Maintaining and preserving the culture and traditions of the country, especially in the terms of tourism development, is of the utmost importance to Qatar. The social landscape of the country is modernized, and globalized, while there is a continued emphasis on the cultural and religious values of the area [6].

\subsubsection{Technological Factors}

Accessibility to smartphones, and phone applications is widespread in the country, and accessibility to online governmental queries and tasks is convenient for the general public. The local community and local businesses are active on social media, and are able to interact with each other faster and more reliably through the technological infrastructure of the country [22].

\subsubsection{Environmental Factors}

With the rapid urban growth of the country and its cities, the environment of Qatar, especially the air quality, is negatively impacted through pollution caused by an increased road traffic, construction sites throughout the country, and by the oilrigs in Qatar. Despite this, ecological efforts have been increased to sustainably conserve the natural heritage of the country, and to protect its biodiversity from the negative impacts of the population growth and urbanization [14].

\subsubsection{Legal Factors}

The legal decisions in Qatar are made by the government, ranging from civil cases to business. Business decisions, particularly investments, are largely made by the government based on the vision it has for the growth of the country for the future [6].

Meinert [11] discusses the relevancy of the time horizon of future scenarios and state that the timeframe for scenarios should be far enough into the future that there is room for the environmental factors to change, and yet are not too far into the future that the scenarios are too irrelevant to the present. The time horizon for scenarios for the future of green cities in Qatar is about 20 to 25 years, as governmental processes and developments progress slowly.

\subsection{Identifying Major Uncertainties}

Based on the PESTLE analysis conducted above, the two main drivers to be discussed are economic growth, and sustainability for the future development of green cities in Qatar.

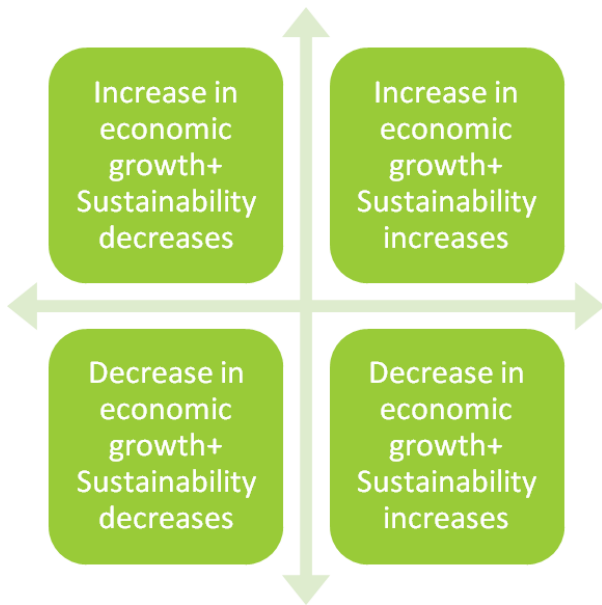

Figure 1. Drivers of Uncertainties.

\subsection{Naming the Alternatives}

In the table below, the alternatives, and extremes are mentioned of the driving forces behind the topic of the future of green cities in Qatar. Drivers such as economic growth, sustainability, governmental support, and carrying capacity are deemed most important as they are the ones to be considered first when it comes to the planning of green cities. This was similarly highlighted by Sofeska [21] by stating that economic growth, sustainability and government support are key drivers for green cities. Rydin [17] explains that governments and municipalities are essential in applying sustainable measures to cities. Forces such as pollution, urban infrastructure, community lifestyle, and real estate trends are considered most uncertain, as they are influenced by external environmental factors, and/or are under the influence of governmental sectors.

Table 1. Alternatives for Driving Forces.

\begin{tabular}{lll}
\hline Extremes & Driving forces & Extremes \\
\hline Tangibility, materialistic & Economic growth & Intangibility, experiential \\
Increased focus & Sustainability & Negligent planning \\
\hline
\end{tabular}




\begin{tabular}{lll}
\hline Extremes & Driving forces & Extremes \\
\hline Expansion & Carrying capacity & Constriction \\
Limited to self & Community lifestyle & Extending to the community \\
Ignorance & Pollution & Action \\
Alternate solutions & Support from the government & Continued support of the present \\
Inclusive of disabled people & Accessibility & Exclusive \\
Care for nature & Environmental and sustainability regulations & Care for people \\
Utilized in sustainability projects & Technological innovations & Too expensive or irrelevant \\
International manpower & Employment & Domestic manpower \\
Increased buyer power & Real estate trends & Decreased buyer power \\
Mobile, comfortable & Urban infrastructure & Limited, obstructing \\
\hline
\end{tabular}

\section{Analysis and Discussions}

\subsection{Calibrating a Future Compass}

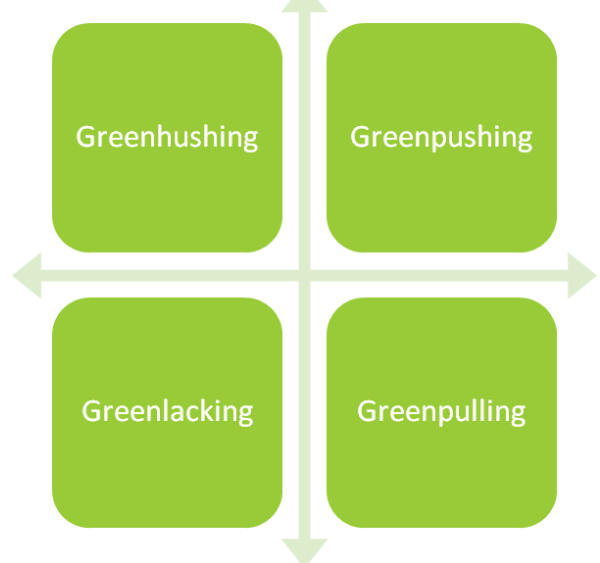

Figure 2 Future Scenarios.

The scenarios above are derived from the main drivers and the extremes of the drivers from step 2 and 3 with regards to the topic of the Future of Green Cities in Qatar in 2040. The main drivers are economic growth, and sustainability, and the extremes of economic growth are materialism, and experientialism, and the extremes of sustainability are increased focus on sustainability, and the negligent planning of urban spaces in Qatar.

\subsection{Creating Scenario Narratives}

\subsubsection{Greenhushing}

The first scenario, greenhushing, is based on the increase in economic growth, and a decrease in sustainability. The growth of the economy allows the country to rise ranks in the global economy [3]. The economic growth is fast paced, with the intent to create more accommodation for increased labor workforce, and tourists. Hotels, and apartment buildings are constructed without regards to the environment and the surroundings, and the lack of focus on sustainability causes the pollution to rise with the increase in the overall population of the country.

Economic growth is done through an increase in tourism, and when tourists visit the country, the demand for entertainment, and leisure activities increases. This again allows for construction of such places, without regard to the infrastructure of the country. Harvey [7] refers to the latter as an issue that most countries face as they tend to achieve the broader goals of sustainability but prioritize economic growth instead. Similarly, Shields [20] describes this as commodified sustainability which can lead to environmental destruction. Urbanization causes an increase in consumption, and the lack of appropriate waste management systems adds to the pollution of Qatar. When tourists or the local population demand for sustainability based on their environmental awareness, the government and city development planners claim to support sustainable development but are not focused on it as it reduces the number of accommodations, and business and leisure infrastructure that needs to be constructed.

The outcome of this scenario is a reduced focus on sustainability, as it is not deemed an important aspect to focus on anymore.

\subsubsection{Greenpushing}

The second scenario, greenpushing, is based on the increase in economic growth, and an increase in sustainability. This narrative is titled greenpushing, as with the increase in urban infrastructure, and economic growth allows for the governmental focus to be on environmental regulation in the country, and strategies that are designed for the promotion of green living in Qatar. Increased economic growth allows connections and accessibility to grow within sectors of the country, and to connect place and people through alternate transportation other than cars, thereby reducing the pollution caused by road transportation. As the traffic congestion decreases, it clears up space for sustainable living space that are close to business areas, which also reduces the time needed to travel to and from work. Quality of life increases, as the cities are designed as such that people spend less time traveling and can have more leisure time to spend by themselves or with their communities.

When there is an increase in sustainability, the local population grows more aware, and wants to live in sustainable environments. Mahgoub and Qawasmeh [10] argue that environmental knowledge education would be necessary as a social era of citizenship to reduce environmental consequences in cities. This would also apply to the city of Doha. The community lifestyle evolves to a more sustainable one, where the focus is on communal green spaces, rather than individual needs and desires. The demographic of the local community reflects technological awareness and are globalized enough to observe the environmental changes worldwide which will help the local environment. This pushes the local community to demand the government for better environmental regulations and ensure that they are willing to play their part in the reduction of waste, and pollution in the country. Mahgoub and Qawasmeh [10] refer to this by suggesting that social cooperation is the 
solution to economic issues. This is the most ideal scenario for the country, as it allows for both the economic growth and sustainable development of the country.

\subsubsection{Greenlacking}

The third scenario, greenlacking, is based on a decrease in economic growth, and a decrease in sustainability. When it comes to greenlacking, the economy of the country sees less growth than predicted, which causes the tightening of budgets for constructing new accommodations and infrastructure. There is also a decrease in sustainable developments, as the focus has reduced due to lack of future vision, and planning. Local environmental awareness interest is also reduced, as the local community is more focused on achieving and maintaining employment. In their description of sustainable planning, Sharpley and Telfer [19] refer to the neglect of environmental sustainability as environmental culture which requires less supervision if the risks of environmental degradation are understood by the community. Sharpley and Telfer [19] argue that when communities lack understandings of environmental issues, this would lead to a catastrophic future for cities and people's lifestyles.

With a decrease in sustainability, the country becomes more polluted, and as the infrastructure continues to be damaged, and natural habitats are negatively impacted as environmental regulations take a backseat with the lack of budget for it. Additionally, the local community becomes stuck in its old ways, and there is a failure to transform and keep up with international growth and lifestyle trends. This relates to Zhou's [27] discussion when suggesting that Cities are investing and planning their futures based on predictions of trends. Zhou [27] further argues that cities not planning appropriately for latest trends will eventually suffer the outcomes of unfavorable events.

This scenario causes the most uncertainty in terms of sustainability, as there is no assurance how the trend can be continued for the future. As economic growth is stunted, gaps appear in the overall national economy, and within the governmental infrastructure of Qatar.

\subsubsection{Greenpulling}

The fourth scenario, greenpulling, is based on a decrease in economic growth, and an increase in sustainability. The decrease in economic growth causes the country to slow its urbanization and observes a decrease in tourist visits. The increase in sustainability is observed through the locals' search for green options to maintain their infrastructure and their urban spaces. The locals are pulled to greener living, as the decrease in economic growth impacts their current lifestyles of consumption. Increase in sustainability can also attract external investments in the country, making the country renowned for its sustainable practices on an international level. Sharpley and Telfer [19] explain how a local community that focusses on green and healthy living unintentionally creates a 'green tourism' industry which boosts the economy while preserving nature.

In this scenario, while the decrease in economic growth causes a decrease in the growth of supporting industries, an increase in sustainability allows for the local community to successfully preserve its urban and natural environments for its future generations.

\subsection{Implications of Future Scenarios and Strategic Options}

The spread of urbanization and the specific problems of urban life have increasingly highlighted the need for comprehensive attention to strategies and practical solutions to optimize the lives of urban residents [5]. Urban management is one of the most important factors for controlling urban development impact as controlling urban environments, urban transport, urban safety, and urban planning, which has an increasing and decisive influence on other factors of urban life [5]. The below mentioned strategic scenarios derived from various literature $([1,2,5,10,17,21$, 27]) that suggests the best means of suitable urban green living.

Table 2. Strategic Options.

\begin{tabular}{ll}
\hline Greenhushing & Greenpushing \\
\hline+ increase in revenue & + high stakeholder involvement \\
+ increase in tourists & + healthy lifestyle \\
+ globalization & + sustainable projects \\
- increase in pollution & - insufficient planning \\
- increase in population & - inability to maintain sustainable spaces \\
- insufficient waste management & - narrow target group \\
Greenlacking & Greenpulling \\
+ opportunities for alternate economic sources & + policymaking \\
+ cultural preservation & + green image \\
+ reconnecting with traditional roots & + sustainability development and promotion \\
- loss of employment & - criticism \\
- increase in inflation & - mistrust from locals \\
- loss of environmental preservation & - negative impacts \\
\hline
\end{tabular}

Table 3. Scenario 1

\begin{tabular}{llll}
\hline & Direct implications & Actions & Taken by \\
\hline & + increase in revenue & Further investments & Government \\
& + increase in tourists & Famous on international level & Government, DMOs \\
Scenario 1 & + globalization & Increase in international products and experiences & Government, local community, visitors \\
Greenhushing & - increase in pollution & Local antagonism & Visitors \\
& - increase in population & Increased urbanization & Government, visitors \\
& - insufficient waste management & Damaged infrastructure & Government, local community, visitors \\
\hline
\end{tabular}


Action 1: Greenhushing allows for the economy to grow, through investments occurring internally in the country and out of the country.

Action 2: When it comes to the increase in tourists, Qatari government and DMOs promote the country as a cultural, business, and leisure destination, and infrastructure grows to meet the needs and wants of the tourists. This is the most important action, as it will help diversify the economy of the country and will help the country rely less on its natural resources.

Action 3: Greenhushing also causes globalization to increase within Qatar, as there is reduced sustainable regulations, whether they are cultural, social, or environmental. This creates a demand of more globalized experiences and products in the country by the locals, and tourists alike, which are readily met by the government in order to continue growing its economy.

Action 4: However, greenhushing will also cause an increase in pollution, as the importance of sustainability will not be communicated with the visitors. This will cause antagonism within the local community, who will view the visitors as enjoying their spaces, and leaving them damaged for the local community.

Action 5: An increase in population will increase urbanization, as housing demands will have to be met by the government in order to accommodate the increase in expatriates, and visitors to the country. As the new economy relies on various types of tourism, with short and long stay visitors, a diversification will also be seen in the types of accommodation offered to the public and could overpopulate urban spaces that have already reached their carrying capacities.

Table 4. Scenario 2.

\begin{tabular}{llll}
\hline & Direct implications & Actions & Taken by \\
\hline & + high stakeholder involvement & Sustainable awareness & All stakeholders \\
& + healthy lifestyle & Active programs & Local community, businesses, private sector, government \\
Scenario 2 & + sustainable projects & Trends management & Government, private sector \\
Greenpushing & - insufficient planning & Commoditization & Government, visitors, private sector \\
& - inability to maintain sustainable spaces & Ghost town & Government, local community \\
& - narrow target group & Saturation & Government, private sector \\
\hline
\end{tabular}

Action 1: In greenpushing, high stakeholder involvement can be seen through an increase in sustainable awareness by all the stakeholders of the community. All stakeholders will play their part in sustainable practices. This is the most important action, as the increase in awareness itself will be sustainable enough to be carried on to future generations.

Action 2: Greenpushing will also see an increase in healthy lifestyles, and increased active programs, through the needs and wants of the local community and visitors, and will be encouraged, and supplied by the government, and local businesses.

Action 3: Sustainable projects will be launched and completed as the trends and demands increase for them. The government and the private sector will be able to successfully complete, and promote them on a national, and international level, and will be welcomed by the local community and visitors alike.

Action 4: On the other hand, there will be insufficient or ineffective planning to predict how the visitors will commoditize the sustainable urban spaces in the country, which will result in the spaces losing their charm, or unique selling point for its inhabitants.

Action 5: With the growth of urban spaces, a drawback will be that they are not managed properly or are made so rapidly that there are not enough inhabitants to occupy them, or that they are built without supporting infrastructure around them. This will cause the urban cities to remain empty and will later turn into ghost towns that are not attracted to any target groups in the country.

Table 5. Scenario 3

\begin{tabular}{|c|c|c|c|}
\hline & Direct implications & Actions & Taken by \\
\hline $\begin{array}{l}\text { Scenario } 3 \\
\text { Greenlacking }\end{array}$ & $\begin{array}{l}\text { + opportunities for alternate economic sources } \\
+ \text { cultural preservation } \\
+ \text { reconnecting with traditional roots } \\
\text { - loss of employment } \\
\text { - increase in inflation } \\
\text { - loss of environmental preservation }\end{array}$ & $\begin{array}{l}\text { Diversification of economy } \\
\text { Cultural awareness } \\
\text { Authenticity } \\
\text { Alternate sources of income } \\
\text { Control of crime } \\
\text { Maintaining natural habitat }\end{array}$ & $\begin{array}{l}\text { Government } \\
\text { Local community } \\
\text { Government, local community } \\
\text { Government, local community } \\
\text { Government } \\
\text { Government, local community }\end{array}$ \\
\hline
\end{tabular}

Action 1: In greenlacking, the first action discussed is the opportunities created for alternate economic sources, through the diversification of the economy by the government. As economic growth is down, the country needs to rely on develop other fields, such as its educational institutes, and become a hub of learning in the region.

Action 2: As sustainability is decreased, there will be a focus on cultural preservation through raising cultural awareness by the local community, as they observe that there is a danger that they could lose their traditions if the culture is not protected by them. This is the most important action, as it shows the local community creating a more active role for themselves in the preservation of their culture and traditions for the future generations.

Action 3: Moreover, greenlacking will see the local community reconnect with their traditional roots, which will make the community more authentic, and true to its traditions. This will attract tourists and visitors that aim to gain authentic experiences and interactions with the local community of the country.

Action 4: As the economy slumps, there is a decrease in employment rates, which causes the government, and the 
local community to create alternate sources of income. There will be a rise in relying on natural resources, such as fishing and pearl diving, but will not prove to be sustainable in the long run.
Action 5: In greenlacking, the economic growth has slowed down, which has caused the local community to turn to crime, as the wage gap is increased. The government will turn stricter in order to control the rate of crimes in Qatar.

Table 6. Scenario 4

\begin{tabular}{llll}
\hline & Direct implications & Actions & Taken by \\
\hline & + policymaking & Increased participation and interaction & Government, private sector \\
& + green image & Transforming the image into reality & Private sector, marketing promotion \\
Scenario 4 & + sustainability development and promotion & Sustainable development & Government, private sector, local community \\
Greenpulling & - criticism & Following green trends & Private sector and businesses \\
& - negative impacts & Monitoring the urban development & Government, local community \\
& - mistrust from locals & Spreading awareness & Government, local community \\
\hline
\end{tabular}

Action 1: The positive impacts of greenpulling include increased governmental support needed for sustainable policymaking. This will allow the development of urban spaces in a sustainable manner, and interaction by the government with the local community.

Action 2: The country will have created a green image for itself and will know how to transform and maintain the image into reality for the public and visitors alike. This will be done through proper planning of green projects, and well executed promotion of the green spaces for its target groups.

Action 3: Sustainable development will increase and will be marketed nationally, and internationally. It will allow for more stakeholder participation within the landscape of the country.

Action 4: However, this could also draw criticism from sustainability watchdogs who claim that the sustainable projects are only for appearances and are executed to keep up with industry trends without any regards to how they actually integrate into the urban landscape of Qatar.

Action 5: This is the most important action to be taken, as the government, and local community will monitor the growth of urban development in the country in order to avoid the negative impacts of urbanization on the local community. This will be a sustainable method to manage urban development and will allow the decision-makers to learn from negative events that will arise during the process of the development.

\section{Conclusions}

The strategic options that are deemed important and relevant to the future of green cities include the promotion of the country as an attractive tourist destination which will cause an increase in tourists, and will capitalize on the growth of the economy and help diversify it, further reducing the country's reliance on its natural resources.

Moreover, stakeholder involvement should be high with regards to the sustainable development of the country. This causes different stakeholders to recognize their particular role, particularly when it comes to raising awareness, and will allow for a better, more cohesive growth of sustainable development in Qatar.

In the case of decreased sustainability, the local community should be empowered enough to recognize its role in the protection of its culture, as this can be actively and independently done by the local community through raising cultural awareness for cultural preservation for their future generations.

\section{References}

[1] Artmann, M., Kohler, M., Meinel, G., Gan, J., \& Ioja, I. (2019). How smart growth and green infrastructure can mutually support each other - A conceptual framework for compact and green cities. Ecological Indicators, 96, $10-22$.

[2] Charfenort, N. (2012). Urban development and social change in Qatar: the Qatar National Vision 2030 and the 2022 FIFA World Cup. Journal of Arabian Studies, 2 (2), 209-230.

[3] Clark, G. (2013). The future of cities: the role of strategic planning. Future Studies Research Journal, 1 (5), 3-32.

[4] Global Green Growth Institute. (2016). Green city strategic planning methodology.

[5] Gössling, S., Scott, D. (2012). Scenario planning for sustainable tourism: an introduction. Journal of Sustainable Tourism, 20 (6), 773-778.

[6] Gregoric, M. (2014). PESTEL analysis of tourism destinations in the perspective of business tourism (MICE). Tourism \& Hospitality Industry 2014, Trends in Tourism and Hospitality Management.

[7] Harvey, D. (2015). Os Limites Do Capital Boitempo, Hedge, England.

[8] Khan, S., \& Zaman, A. U. (2018). Future cities: Conceptualizing the future based on a critical examination of existing notions of cities. Cities, 72, 217-225.

[9] Klooster, S. A., \& Asselt, M. B. (2006). Practising the scenario-axes technique. Futures, 38 (1), 15-30.

[10] Mahgoub, Y., Qawasmeh, R. A., (2012). Cultural and Economic Influences on Multicultural Cities: The Case of Doha, Qatar. Open House International, 37 (2), 33.

[11] Meinert, S. (2014). Field manual: Scenario building. European Trade Union Institute.

[12] Qatar 2019. (2019). Retrieved 10 May, 2019, from https://countryeconomy.com/countries/qatar.

[13] QBGC. (2019). Qatar Green Building Council. Together Lets Build a Sustainable Future. Retrieved May 18, 2019 from https://qatargbc.org/aboutus/qgbc-qnv2030.

[14] QNA. (2019). Minister highlights efforts to save wildlife, environment. Gulf Times. Retrieved April 2, 2019, from https://www.gulf-times.com/story/627289/Ministerhighlights-efforts-to-save-wildlife-envir. 
[15] Reuters. (2018). UPDATE 1-Qatar's economy "stronger than before", central bank governor says. Reuters. Retrieved April 2, 2019, from https://www.reuters.com/article/qatarcenbank/update-1-qatars-economy-stronger-than-beforecentral-bank-governor-says-idUSL8N1YF14U.

[16] Rizzo, A. (2016). Sustainable urban development and green megaprojects in the Arab states of the Gulf Region: Limitations, covert aims, and unintended outcomes in Doha, Qatar. International Planning Studies, 22 (2), 85-98.

[17] Rydin, Y. (2010). Governing for Sustainable Urban Development. London, Earthscan.

[18] Schiermeier, Q. (2014). The parched planet: Water on tap. Nature News, 510 (7505), 326.

[19] Sharpley, R., Telfer, D. J., (2015). Tourism and development in the developing world. Routledge.

[20] Shields, R. (1998). London and New York: Routledge Encyclopedia of Philosophy, London.

[21] Sofeska, E. (2016). Relevant Factors in Sustainable Urban Development of Urban Planning Methodology and Implementation of Concepts for Sustainable Planning. Improving Sustainability Concept in developing Countries. Elsevier, 140-151.
[22] The Peninsula. (2019). Technological advancement. The Peninsula. Retrieved April 2, 2019, from https://www.thepeninsulaqatar.com/article/30/01/2019/Techno logical-advancement.

[23] Wiedmann, F., Salama, A. M., \& Mirincheva, V. (2014). Sustainable urban qualities in the emerging city of Doha. Journal of Urbanism: International Research on Placemaking and Urban Sustainability, 7 (1), 62-84.

[24] Yeoman, I. (2004). Developing a scenario planning process using a blank piece of paper. Tourism and Hospitality Research, 5 (3), 273-285.

[25] Youssef, H. (2017). The future of sustainable urban development in Qatar. QGBC.

[26] Zaina, S., Zaina, S., \& Furlan, R. (2016). Urban planning in Qatar: Strategies and vision for the development of transit villages in Doha. Australian Planner, 53 (4), 286-301.

[27] Zhou, J. (2015). Urban Complexity and Planning: Theories and Computer Simulations. The Town Planning Review, 86 (1), 117. 